\title{
Analysis of Histological Grade in Resected Lung-invasive Adenocarcinoma
}

\author{
MOTOAKI YASUKAWA ${ }^{1}$, CHIHO OHBAYASHI ${ }^{2}$, TAKESHI KAWAGUCHI ${ }^{1}$, NORIKAZU KAWAI ${ }^{1}$, \\ TOKIKO NAKAI ${ }^{2}$, NORIYOSHI SAWABATA ${ }^{1}$ and SHIGEKI TANIGUCHI ${ }^{1}$ \\ ${ }^{1}$ Department of Thoracic and Cardiovascular Surgery, \\ Nara Medical University School of Medicine, Kashihara, Japan; \\ ${ }^{2}$ Department of Diagnostic Pathology, Nara Medical University School of Medicine, Kashihara, Japan
}

\begin{abstract}
Background/Aim: Although the histological grading systems (Grading) with respect to lung adenocarcinoma are defined using architectural approaches in the eighth cancer Tumor, Node, and Metastasis (TNM) Classification, the prognostic value of the architectural subtypes in advanced stages of the disease remains unclear. We aimed to assess which Grading was more suitable as a prognostic factor: i) (conventional) Grading based on differentiation or ii) (new) Grading based on architectural subtypes. Patients and Methods: We analyzed the outcomes and Gradings of resected 449 patients with adenocarcinoma using receiver operating characteristic (ROC) curves. Results: The tumor histological grade of 147 out of 449 patients changed using the results from the revised Grading. In these 147 patients, ROC curves showed that the area under the curve was 0.710 using the conventional Grading and 0.567 using the new Grading. Conclusion: The conventional Grading might be more suitable for lung adenocarcinoma recurrence compared to the new Grading.
\end{abstract}

Lung cancer is one of the most frequent types of cancer and one of the most lethal ones worldwide (1). Although there is rapid progress in medical treatment, non-small cell lung cancer (NSCLC) has a poor prognosis with a 5-year relative survival rate in about $15 \%$ of patients (2). To manage the prognosis of NSCLC patients and predict the benefits of adjuvant chemotherapy, it is important to identify accurate and practical biomarkers (2).

Histological grading may be helpful for lung cancer management, however, no well-established histological

Correspondence to: Motoaki Yasukawa, Department of Thoracic and Cardiovascular Surgery, Nara Medical University School of Medicine, Kashihara, Nara 634-0822, Japan. Tel: +81 744223051, Fax: +81 744248040, e-mail: myasukawa@naramed-u.ac.jp

Key Words: Lung adenocarcinoma, histological grade, prognosis. grading system with clearly defined criteria exists for lung adenocarcinoma (3, 4). In 2011, the International Association for the Study of Lung Cancer, the American Thoracic Society, and the European Respiratory Society (IASLC/ATS/ERS) proposed a new classification of lung adenocarcinoma, simply based on histological subtypes and a revised histological grading system (4). Previous studies have indicated that this new histological grading based on architectural subtypes has been associated with a better prognosis in stage I lung adenocarcinoma (5-7). On the other hand, an association between a better prognosis of more advanced stages of lung adenocarcinoma, and the new histological grading remains unclear (8). Furthermore, the invasive adenocarcinoma subtypes are classified predominantly according to the greatest percentage of histological component subtype (4). This means that the predominant subtype classification might not reflect the progressive phase of invasive adenocarcinoma.

Here, we assessed which grading system is more suitable for a better prognosis in all stages of completely resected lung invasive adenocarcinoma: i) the histological grading system, based on tumor cell differentiation (the conventional histological grading system) or ii) the histological grading, based on architectural predominant subtypes (the new histological grading system). In this study, we retrospectively reviewed and analyzed the outcomes of 449 patients who underwent complete resection of lung invasive adenocarcinoma of all stages, with a focus on the type of histological grading system.

\section{Patients and Methods}

Patients. We enrolled 449 patients with complete resected pathologic lung invasive adenocarcinoma who underwent lobectomy or pneumonectomy with systematic lymphadenectomy at the Nara Medical University Hospital from January 2010 to December 2016. Patients with additional malignant diseases were excluded from this study. We used video-assisted thoracoscopic surgery using a standardized three-port approach to resect the tumors. The medical 
record of each patient was reviewed, and the pathological (p) T descriptor was reclassified, based on the 8th edition of the Tumor, Node, and Metastasis (TNM) staging (9). In addition, the histological grade was reclassified, based on the 8th edition of the TNM staging and was defined as new grade: i) G1 for lepidic adenocarcinoma, ii) G2 for acinar adenocarcinoma and Papillary adenocarcinoma, and iii) G3 for micropapillary adenocarcinoma and Solid adenocarcinoma) (9). According to the classification based on the 7th edition of the TNM staging (10), conventional grade is as follows: i) G1 for well differentiated adenocarcinoma, ii) G2 for moderately differentiated adenocarcinoma, and iii) G3 for poorly differentiated adenocarcinoma. In this study, the new grading system classifications $\mathrm{G} 1, \mathrm{G} 2, \mathrm{G} 3$ were defined as $\mathrm{nG} 1$, $\mathrm{nG} 2$, $\mathrm{nG} 3$, respectively, and the conventional grading system classifications G1, G2, G3 were defined as cG1, cG2, cG3, respectively.

Each patient received medical checkups and chest X-ray examinations at least twice a year and whole-body computed tomography (CT) scans every six to twelve months during the first two years following surgical intervention and yearly thereafter. The observation period was terminated on the 30th of November 2018. This retrospective study was approved by our institute Ethics Review Board (No. 1774).

Statistical analyses. The chi-square test or Fisher's exact test were used, as appropriate, to examine the association between the two groups. Overall survival and recurrence-free survival were defined as the time from the operation to death from any cause and the first cancer relapse, respectively. Overall survival curves and recurrencefree survival curves were plotted using the Kaplan-Meier method, and the statistically significant differences between groups were assessed using the log-rank test. Univariate and multivariate Cox regression analyses were used to evaluate the hazard ratio with the endpoint of overall survival or recurrence-free survival. Age, sex, pathological diameter of tumor infiltration, ground glass nodules (GGN) on CT, pT descriptor, pN descriptor, histological type, histological grade (according to the conventional or the new classification), pleural invasion factor (PL factor), vascular invasion factor (V factor), lymphatic vessel invasion factor (LY factor), pStage, and preoperative carcinoembryonic antigen (CEA) concentration were included in the univariate analysis. Covariates found to be significant on the univariate analyses were included in the multivariate analysis. A two-sided $p$-value of less than 0.05 was considered statistically significant. All analyses were performed using EZR on R commander version 1.33 (Saitama Medical Center, Jichi Medical University, Japan) (11).

\section{Results}

During the follow-up (median 46 months, range 0-102 months), lung adenocarcinoma recurrence was identified in $23.8 \%$ of patients $(107 / 449)$ and death occurred in $8.7 \%$ $(39 / 449)$ of patients. The overall 5-year survival rate was $89.1 \%$ (95\% confidence interval (CI): 85.1-92.1\%), and the 5 -year recurrence-free survival rate was $73.6 \%$ (95\% CI: $68.1-78.4 \%$ ). Table I shows the clinicopathological characteristics of all patients.

Based on the conventional grading system, there were 209 patients $(46.5 \%)$ in the well-differentiated adenocarcinoma group (cG1), 174 patients $(38.8 \%)$ in the moderately differentiated adenocarcinoma group (cG2), and 66 patients $(14.7 \%)$ in the poorly differentiated adenocarcinoma group (cG3). Using the new grading system, a total of 147 patients $(32.7 \%)$ were in the lepidic adenocarcinoma group (nG1), 226 patients $(50.3 \%)$ were in the acinar or papillary adenocarcinoma group (nG2), and 76 patients $(16.9 \%)$ in the solid or micropapillary adenocarcinoma group (nG3). The tumor histological grade changed in $32.7 \%$ (147/449) of patients using the revised grading system during the observation period (Table II).

In a total of 449 patients, the 5-year overall survival rates in the $\mathrm{cG} 1, \mathrm{cG} 2$, and cG3 groups (using the conventional grading system) were $97.0 \%$ (95\% CI: $92.0 \%-98.9 \%$ ), $85.9 \%$ (95\% CI: $78.3 \%-91.0 \%$ ), and $70.0 \%$ (95\% CI: $53.3 \%-$ $81.7 \%)$, respectively $(p<0.001)$ (Figure $1 \mathrm{~A})$. The 5 -year recurrence-free survival rates in the $\mathrm{cG} 1, \mathrm{cG} 2$, and $\mathrm{cG} 3$ groups were $94.0 \%$ (95\% CI: 88.1\%-97.0\%), 63.7\% (95\% CI: $53.8 \%-72.1 \%$ ), and $34.2 \%$ (95\% CI: $20.4 \%-48.5 \%$ ), respectively $(p<0.001)$ (Figure $1 \mathrm{~B})$. On the other hand, using the new grading system, the 5-year overall survival rates in the $\mathrm{nG} 1, \mathrm{nG} 2$, and $\mathrm{nG} 3$ groups were $98.6 \%$ (95\% CI: $94.3 \%$ 99.6\%), 88.5\% (95\% CI: $82.2 \%-92.7 \%)$, and $69.7 \%(95 \%$ CI: $54.1 \%-80.9 \%)$, respectively $(p<0.001)$ (Figure $2 \mathrm{~A})$. The 5 -year recurrence-free survival rates in the $\mathrm{nG} 1, \mathrm{nG} 2$, and nG3 groups were $95.0 \%$ (95\% CI: $88.0 \%-98.0 \%$ ), $69.1 \%$ (95\% CI: $61.0 \%-75.8 \%$ ), and $45.1 \%$ (95\% CI: $30.1 \%-$ $59.0 \%)$, respectively $(p<0.001)$ (Figure $2 \mathrm{~B})$.

Analysis of relative risks showed that the age, the sex, the pathological diameter of tumor infiltration, pure GGN on CT, the histological grade (using both new and conventional grading systems), the PL, V and LY factors, the pT and $\mathrm{pN}$ descriptors, the pStage, and the preoperative CEA concentration were indicators of overall survival (Table III). Multivariate analysis showed that the histological grade (conventional grade), the pT and $\mathrm{pN}$ descriptors were independent predictors of overall survival in cases classified using the conventional grading system (Table IV). Regarding the new grading system, the multivariate analysis also showed that the histological grade (new grade), the $\mathrm{pT}$ and $\mathrm{pN}$ descriptors were independent predictors of overall survival (Table V).

Conversely, the analysis of relative risk with the endpoint of cancer recurrence showed that the pathological diameter of tumor infiltration, the pure GGN on CT, the histological grade (using both new and conventional grading systems), the PL, V and LY factors, the micropapillary, the pStage, the pT and $\mathrm{pN}$ descriptors, and the preoperative CEA concentration were indicators of cancer recurrence (Table VI). The multivariate analysis showed that the pathological diameter of tumor infiltration, the $\mathrm{pN}$ descriptor, the histological grade (conventional grading), and the $\mathrm{V}$ factor were independent predictors of recurrence using the conventional grading system (Table VII). Regarding the new grading system, multivariate analysis showed that the pathological diameter 
Table I. Clinicopathological characteristics of the study population $(n=449)$.

\begin{tabular}{|c|c|}
\hline Characteristics & $\mathrm{N}(\%)$ \\
\hline \multicolumn{2}{|l|}{ Age } \\
\hline$<70$ Years & $239(53.2)$ \\
\hline$\geq 70$ Years & $210(46.8)$ \\
\hline \multicolumn{2}{|l|}{ Gender } \\
\hline Male & $240(53.5)$ \\
\hline Female & $209(46.5)$ \\
\hline \multicolumn{2}{|l|}{ CT findings } \\
\hline Pure GGN & $96(21.4)$ \\
\hline Other & $353(78.6)$ \\
\hline \multicolumn{2}{|l|}{ Location } \\
\hline Peripheral & $366(81.5)$ \\
\hline Other & $83(18.5)$ \\
\hline \multicolumn{2}{|l|}{ pStage } \\
\hline I & $342(76.2)$ \\
\hline$\geq \mathrm{II}$ & $107(23.8)$ \\
\hline \multicolumn{2}{|l|}{ pT descriptor } \\
\hline Tmin & $13(2.9)$ \\
\hline T1a & $30(6.7)$ \\
\hline $\mathrm{T} 1 \mathrm{~b}$ & $136(30.3)$ \\
\hline $\mathrm{T} 1 \mathrm{c}$ & $105(23.4)$ \\
\hline $\mathrm{T} 2 \mathrm{a}$ & $115(25.6)$ \\
\hline $\mathrm{T} 2 \mathrm{~b}$ & $22(4.9)$ \\
\hline$\geq \mathrm{T} 3$ & $28(6.2)$ \\
\hline \multicolumn{2}{|c|}{ Invasive size of tumor } \\
\hline$\leq 30 \mathrm{~mm}$ & $337(75.1)$ \\
\hline$>30 \mathrm{~mm}$ & $112(24.9)$ \\
\hline \multicolumn{2}{|l|}{ pN descriptor } \\
\hline $\mathrm{pNO}$ & $375(83.5)$ \\
\hline pN1 & $42(9.4)$ \\
\hline$\geq \mathrm{pN} 2$ & $32(7.1)$ \\
\hline \multicolumn{2}{|c|}{ Histological grade (conventional) } \\
\hline cG1 & $209(72.1)$ \\
\hline cG2 & $174(38.8)$ \\
\hline cG3 & $66(14.7)$ \\
\hline \multicolumn{2}{|c|}{ Histological grade (new) } \\
\hline nG1 & $147(32.7)$ \\
\hline nG2 & $226(50.3)$ \\
\hline nG3 & $76(16.9)$ \\
\hline \multicolumn{2}{|l|}{ PL } \\
\hline Present & $98(21.8)$ \\
\hline Absent & $351(78.2)$ \\
\hline \multicolumn{2}{|l|}{ LY } \\
\hline Present & $165(36.7)$ \\
\hline Absent & $284(63.3)$ \\
\hline \multicolumn{2}{|l|}{$\mathrm{V}$} \\
\hline Present & $140(31.2)$ \\
\hline Absent & $309(68.8)$ \\
\hline \multicolumn{2}{|l|}{ EGFR mutation } \\
\hline Present & $75(22.4)$ \\
\hline Absent & $260(77.6)$ \\
\hline \multicolumn{2}{|l|}{ CEA } \\
\hline$<5 \mathrm{ng} / \mathrm{ml}$ & $328(73.1)$ \\
\hline$\geq 5 \mathrm{ng} / \mathrm{ml}$ & $121(26.9)$ \\
\hline \multicolumn{2}{|l|}{ Recurrence } \\
\hline Yes & $107(23.8)$ \\
\hline No & $342(76.2)$ \\
\hline \multicolumn{2}{|l|}{ Survival } \\
\hline Yes & $410(91.3)$ \\
\hline No & $39(8.7)$ \\
\hline
\end{tabular}

CEA: Carcinoembryonic antigen, CT: computed tomography; GGN ground glass nodule; LY: lymphatic vessel invasion factor; PL: pleural invasion factor, V: vascular invasion factor.
Table II. Univariate analysis of factors associated with the revised grading system considering all patients.

\begin{tabular}{|c|c|c|c|}
\hline Characteristics & $\begin{array}{l}\text { Without change } \\
\qquad(\mathrm{n}=302)\end{array}$ & $\begin{array}{l}\text { With change } \\
\quad(\mathrm{n}=147)\end{array}$ & $p$-Value \\
\hline \multicolumn{4}{|l|}{ Age } \\
\hline$<70$ Years & $154(51.0)$ & $85(57.8)$ & \multirow[t]{2}{*}{0.191} \\
\hline$\geq 70$ Years & $148(49.0)$ & $62(42.2)$ & \\
\hline \multicolumn{4}{|l|}{ Gender } \\
\hline Male & $158(52.3)$ & $82(55.8)$ & \multirow[t]{2}{*}{0.545} \\
\hline Female & $144(47.7)$ & $65(44.2)$ & \\
\hline \multicolumn{4}{|l|}{ CT findings } \\
\hline Pure GGN & $72(23.8)$ & $24(16.3)$ & \multirow[t]{2}{*}{0.086} \\
\hline Other & $230(76.2)$ & $123(83.7)$ & \\
\hline \multicolumn{4}{|l|}{ Location } \\
\hline Peripheral & $240(79.5)$ & $126(85.7)$ & \multirow[t]{2}{*}{0.121} \\
\hline Other & $62(20.5)$ & $21(14.3)$ & \\
\hline \multicolumn{4}{|l|}{ pStage } \\
\hline I & $232(76.8)$ & $110(74.8)$ & \multirow[t]{2}{*}{0.639} \\
\hline$\geq \mathrm{II}$ & $70(23.2)$ & $37(25.2)$ & \\
\hline \multicolumn{4}{|l|}{ pT descriptor } \\
\hline Tmin & $12(4.0)$ & $1(0.7)$ & \multirow[t]{7}{*}{ NA } \\
\hline T1a & $21(7.0)$ & $9(6.1)$ & \\
\hline $\mathrm{T} 1 \mathrm{~b}$ & $89(29.5)$ & $47(32.0)$ & \\
\hline $\mathrm{T} 1 \mathrm{c}$ & $67(22.2)$ & $38(25.9)$ & \\
\hline T2a & $75(24.8)$ & $40(27.2)$ & \\
\hline $\mathrm{T} 2 \mathrm{~b}$ & $18(6.0)$ & $4(2.7)$ & \\
\hline$\geq \mathrm{T} 3$ & $20(6.6)$ & $8(5.4)$ & \\
\hline \multicolumn{4}{|c|}{ Invasive size of tumor } \\
\hline$\leq 30 \mathrm{~mm}$ & $222(73.5)$ & $115(78.2)$ & \multirow[t]{2}{*}{0.297} \\
\hline$>30 \mathrm{~mm}$ & $80(26.5)$ & $32(21.8)$ & \\
\hline \multicolumn{4}{|l|}{ pN descriptor } \\
\hline pNO & $256(84.8)$ & $119(81.0)$ & \multirow[t]{3}{*}{0.562} \\
\hline pN1 & $26(8.6)$ & $16(10.9)$ & \\
\hline$\geq \mathrm{pN} 2$ & $20(6.6)$ & $12(8.2)$ & \\
\hline \multicolumn{4}{|c|}{ Histological grade (conventional) } \\
\hline cG1 & $128(42.4)$ & $81(55.1)$ & 0.028 \\
\hline $\mathrm{cG} 2$ & $129(42.7)$ & 45 (30.6) & \\
\hline $\mathrm{cG} 3$ & 45 (14.9) & $21(14.3)$ & \\
\hline Histological gra & & & \\
\hline nG1 & $129(42.7)$ & $18(12.2)$ & $<0.001$ \\
\hline nG2 & $128(42.4)$ & $98(66.7)$ & \\
\hline nG3 & 45 (14.9) & $31(21.1)$ & \\
\hline PL & & & \\
\hline Present & $61(20.2)$ & 37 (25.2) & 0.273 \\
\hline Absent & $241(79.8)$ & $110(74.8)$ & \\
\hline LY & & & \\
\hline Present & $97(32.1)$ & $68(46.3)$ & 0.005 \\
\hline Absent & 205 (67.9) & $79(53.7)$ & \\
\hline V & & & \\
\hline Present & $85(28.1)$ & $55(37.4)$ & 0.051 \\
\hline Absent & 217 (71.9) & $92(62.6)$ & \\
\hline EGFR mutation & & & \\
\hline Present & $41(18.7)$ & $34(29.3)$ & 0.038 \\
\hline Absent & $178(81.3)$ & $82(70.7)$ & \\
\hline CEA & & & \\
\hline$<5 \mathrm{ng} / \mathrm{ml}$ & $229(75.8)$ & 99 (67.3) & 0.070 \\
\hline$\geq 5 \mathrm{ng} / \mathrm{ml}$ & 73 (24.2) & $48(32.7)$ & \\
\hline Recurrence & & & \\
\hline Yes & $74(24.5)$ & 33 (22.4) & 0.723 \\
\hline No & $228(75.5)$ & 114 (77.6) & \\
\hline Survival & & & \\
\hline Yes & $276(91.4)$ & $134(91.2)$ & 1.000 \\
\hline No & $26(8.6)$ & $13(8.8)$ & \\
\hline
\end{tabular}

CEA: Carcinoembryonic antigen; CT: computed tomography; GGN: ground glass nodule; LY: lymphatic vessel invasion factor; NA: not applicable; PL: pleural invasion factor, V: vascular invasion factor. 

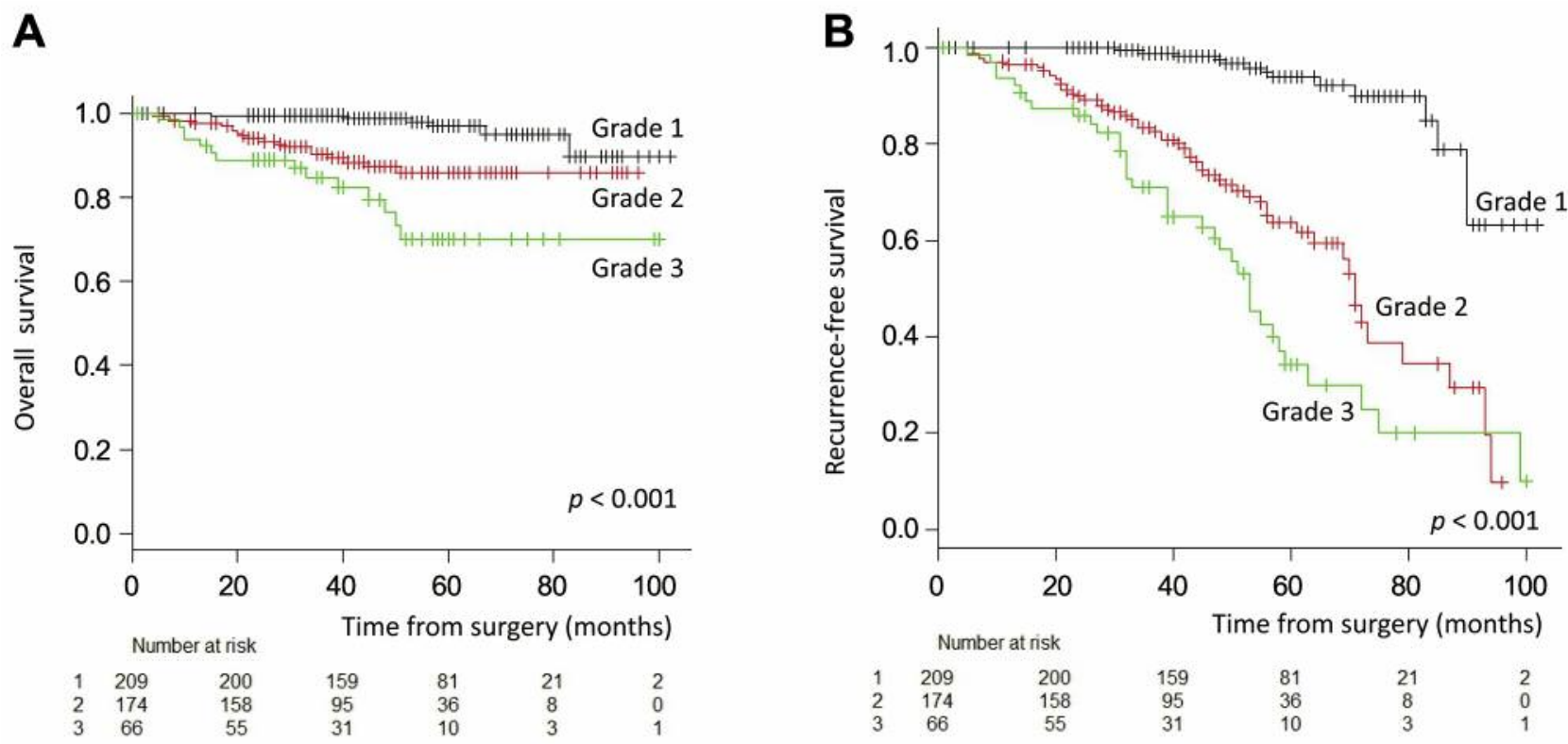

Figure 1. (A) Overall survival curve of all patients according to the conventional histological grading. The 5-year overall survival rates were $97.0 \%$ in the cG1 group, $85.9 \%$ in the cG2 group, and $70.0 \%$ in the $c G 3$ group $(p<0.001)$. (B) Recurrence-free survival curve of all patients according to the conventional histological grading. The 5-year recurrence-free survival rates were $94.0 \%$ in the cG1 group, $63.7 \%$ in the cG2 group, and $34.2 \%$ in the $c G 3$ group $(p<0.001)$.

A

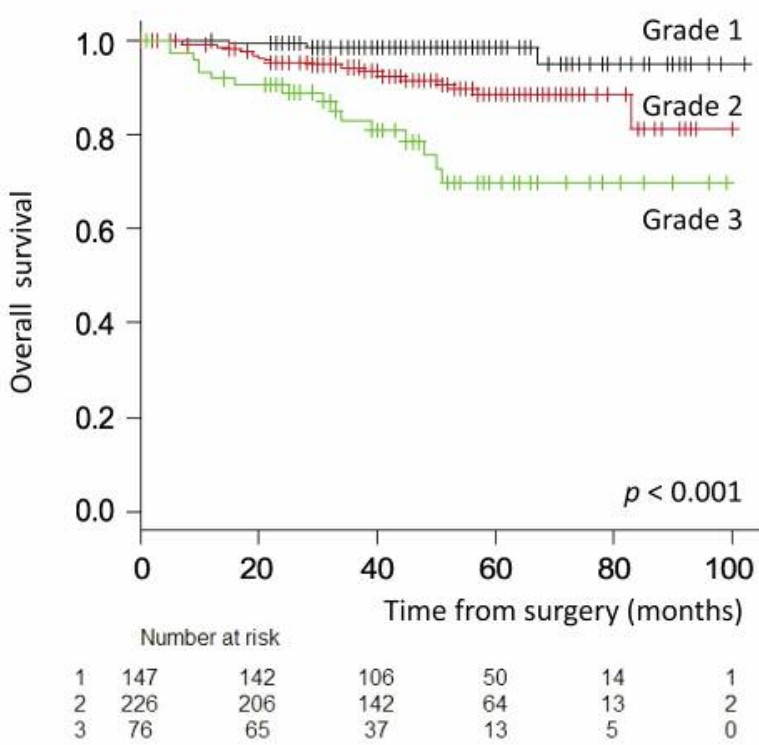

B

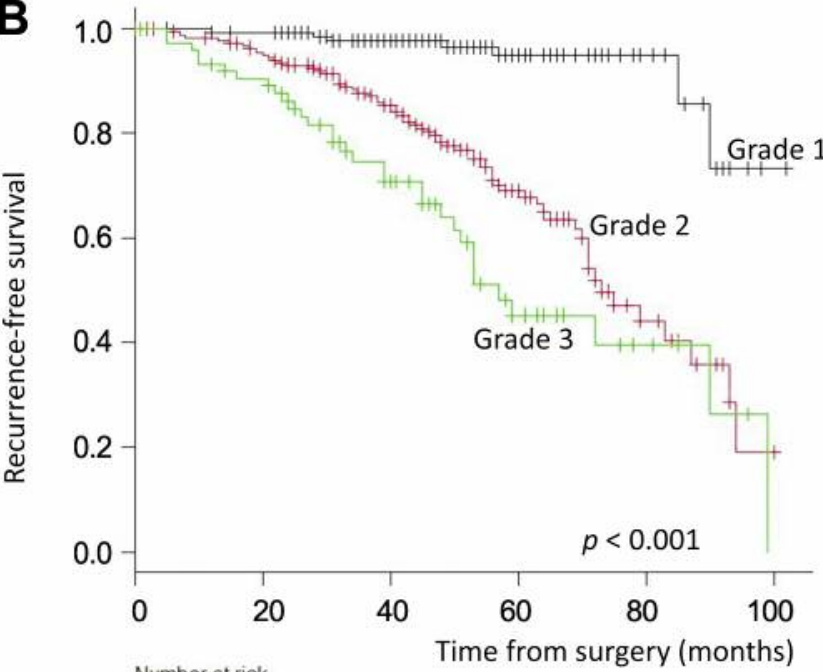

Number at risk

$\begin{array}{ccccccc}1 & 147 & 142 & 106 & 50 & 14 & 1 \\ 2 & 226 & 206 & 142 & 64 & 13 & 2 \\ 3 & 76 & 65 & 37 & 13 & 5 & 0\end{array}$

Figure 2. (A) Overall survival curve of all patients according to the new histological grading. The 5-year overall survival rates were $98.6 \%$ in the $n G 1$ group, $88.5 \%$ in the $n G 2$ group, and $69.7 \%$ in the $n G 3$ group $(p<0.001)$. (B) Recurrence-free survival curve of all patients according to the new histological grading. The 5-year recurrence-free survival rates were $95.0 \%$ in the $n G 1$ group, $69.1 \%$ in the $n G 2$ group, and $45.1 \%$ in the $n G 3$ group ( $p<0.001$ ).

of tumor infiltration, the $\mathrm{pN}$ descriptor, and the $\mathrm{V}$ factor were independent predictors of cancer recurrence (Table VIII). Using the new histological grading system no independent predictors of cancer recurrence were identified.
Furthermore, due to evaluating and the revision of the histological grading system, all 449 patients were reevaluated and were checked up on the changed grade (Table II). From these, we analyzed the 147 cases that changed 

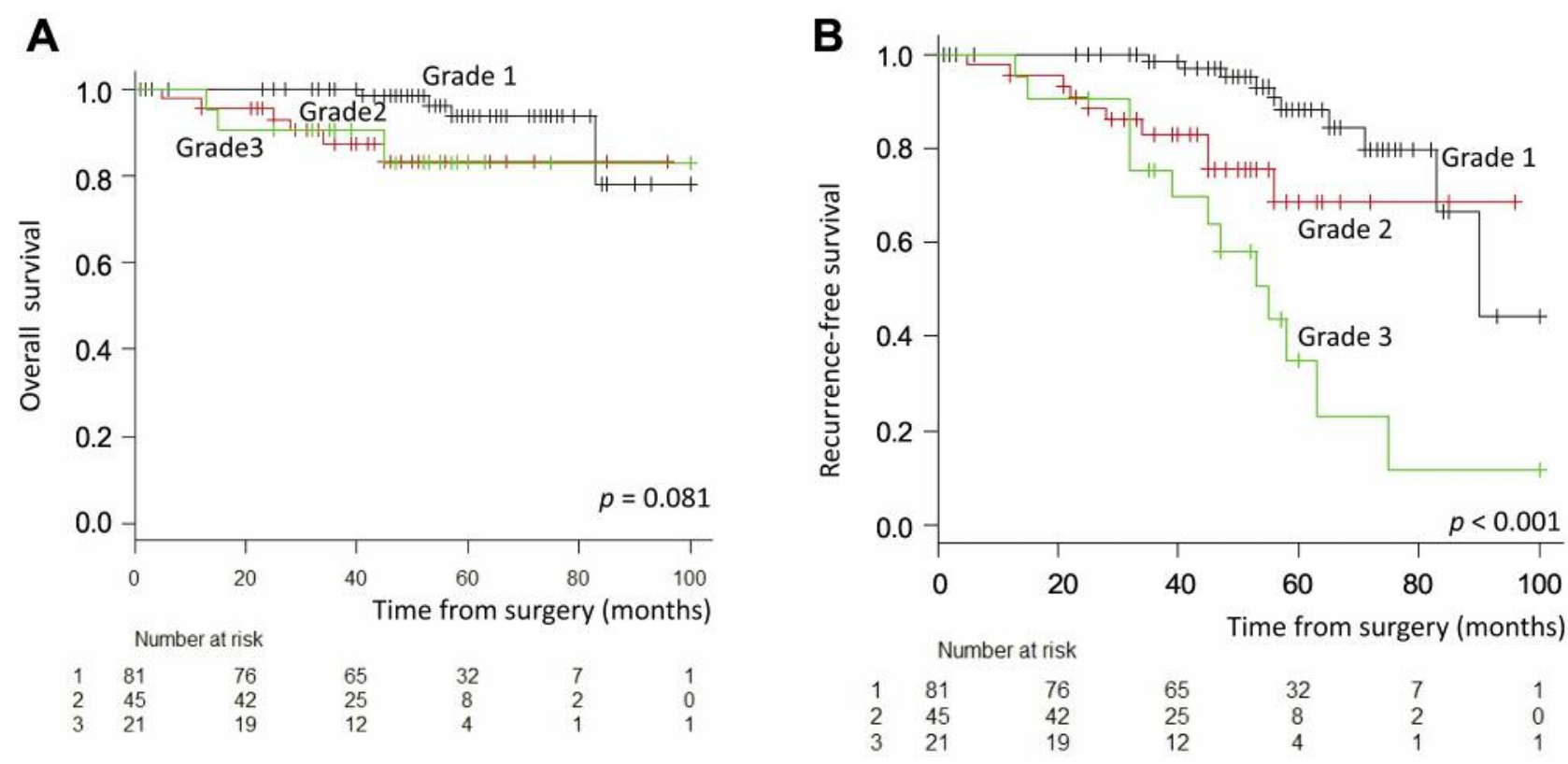

Figure 3. (A) Overall survival curve of 147 patients who changed histological grade according to conventional histological grading. The 5-year overall survival rates were $93.7 \%$ in the cG1 group, $83.3 \%$ in the cG2 group, and $82.9 \%$ in the cG3 group (p=0.081). (B) Recurrence-free survival curve of 147 patients who changed histological grade according to conventional histological grading. The 5-year recurrence-free survival rates were $88.3 \%$ in the cG1 group, $68.6 \%$ in the cG2 group, and $34.8 \%$ in the $c G 3$ group $(p<0.001)$.
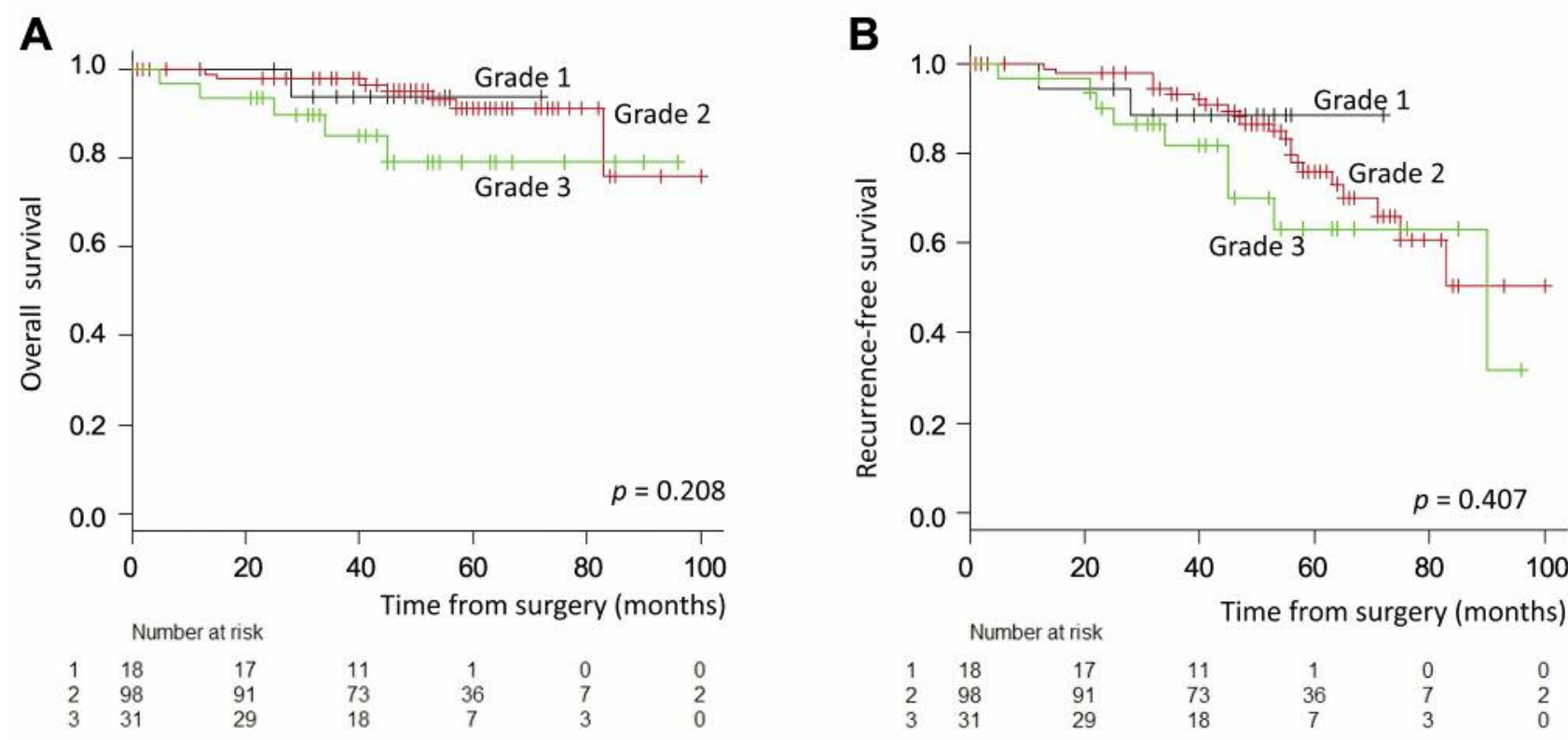

Figure 4. (A) Overall survival curve of 147 patients who changed histological grade according to new histological grading. The 5-year overall survival rates were $93.8 \%$ in the $n G 1$ group, $91.1 \%$ in the $n G 2$ group, and $79.0 \%$ in the $n G 3$ group $(p=0.208)$. (B) Recurrence-free survival curve of 147 patients who changed histological grade according to new histological grading. The 5-year recurrence-free survival rates were $88.5 \%$ in the $n G 1$ group, $75.9 \%$ in the $n G 2$ group, and $63.1 \%$ in the $n G 3$ group $(p=0.407)$.

histological grade. Among the 147 patients, the 5-year overall survival rates in the $\mathrm{cG} 1, \mathrm{cG} 2$, and $\mathrm{cG} 3$ groups (using the conventional grading system) were $93.7 \%$ (95\% CI: $81.4 \%-98.0 \%$ ), $83.3 \%$ (95\% CI: $65.7 \%-92.3 \%$ ), and $82.9 \%$
(95\% CI: $54.5 \%-94.4 \%)$, respectively ( $p=0.081$ ) (Figure $3 \mathrm{~A})$. The 5 -year recurrence-free survival rates in the $\mathrm{cG} 1$, cG2, and cG3 groups were $88.3 \%$ (95\% CI: $75.5 \%-94.7 \%$ ), $68.6 \%$ (95\% CI: $46.4 \%-83.1 \%$ ), and $34.8 \%$ (95\% CI: $12.7 \%$ - 
Table III. Univariate analysis of factors influencing the survival of all patients after complete resection of the primary lung cancer.

\begin{tabular}{|c|c|c|c|c|}
\hline Factors & Comparison & Hazard ratio & $95 \% \mathrm{CI}$ & $p$-Value \\
\hline Age & $\geq 70 v s .<70$ years & 2.291 & $1.188-4.417$ & 0.013 \\
\hline Gender & Male $v s$. female & 2.070 & $1.048-4.087$ & 0.036 \\
\hline CT findings & Pure GGN $v s$. other & 0.090 & $0.012-0.656$ & 0.017 \\
\hline Location & Peripheral $v s$. other & 0.717 & $0.349-1.474$ & 0.366 \\
\hline Histological grade (conventional) & $\mathrm{cG} 2+3$ vs. $\mathrm{cG} 1$ & 2.936 & $1.930-4.467$ & $<0.001$ \\
\hline Histological grade (new) & $\mathrm{nG} 2+3$ vs. nG1 & 3.271 & $2.020-5.299$ & $<0.001$ \\
\hline pStage & $\geq \mathrm{II} v s . \mathrm{I}$ & 9.488 & $4.796-18.77$ & $<0.001$ \\
\hline $\mathrm{pT}$ & $\geq 2 v s . \leq 1$ & 4.362 & $2.208-8.616$ & $<0.001$ \\
\hline Invasive size of tumor & $>30 v s . \leq 30 \mathrm{~mm}$ & 3.790 & $2.018-7.117$ & $<0.001$ \\
\hline $\mathrm{pN}$ & $\geq 1$ vs. 0 & 2.347 & $1.624-3.392$ & $<0.001$ \\
\hline PL & Present $v s$. absent & 4.111 & $2.189-7.719$ & $<0.001$ \\
\hline V & Present $v s$. absent & 6.942 & $3.450-13.97$ & $<0.001$ \\
\hline LY & Present $v s$. absent & 5.355 & 2.609-10.99 & $<0.001$ \\
\hline Micropapillary & Present $v s$. absent & 1.906 & $0.744-4.881$ & 0.1789 \\
\hline CEA & $\geq 5 \mathrm{vs} .<5 \mathrm{ng} / \mathrm{ml}$ & 2.493 & $1.328-4.682$ & 0.004 \\
\hline
\end{tabular}

CEA: Carcinoembryonic antigen; CI: confidence interval; CT: computed tomography; GGN: ground glass nodule; LY: lymphatic vessel invasion factor; PL: pleural invasion factor; V: vascular invasion factor.

Table IV. Multivariate analysis of factors influencing the survival of all patients after complete resection of the primary lung cancer using the conventional grading system.

\begin{tabular}{llccc}
\hline & Comparison & Hazard ratio & $95 \%$ CI & $p$-Value \\
\hline pT & $\geq 2$ vs. $\leq 1$ & 2.560 & $1.240-5.288$ & 0.011 \\
pN & $\geq 1$ vs. 0 & 1.580 & $1.051-2.375$ & 0.028 \\
Histological grade (conventional) & cG2+3 vs.cG1 & 2.023 & $1.259-3.249$ & 0.004 \\
\hline
\end{tabular}

Table V. Multivariate analysis of factors influencing the survival of all patients after complete resection of the primary lung cancer using the new grading system.

\begin{tabular}{llccc}
\hline & Comparison & Hazard ratio & $95 \%$ CI & $p$-Value \\
\hline pT & $\geq 2$ vs. $\leq 1$ & 2.487 & $1.181-5.238$ & 0.016 \\
pN & $\geq 1$ vs. 0 & 1.585 & $1.041-2.413$ & 0.032 \\
Histological grade (new) & nG2+3 vs.nG1 & 2.176 & $1.270-3.726$ & 0.005 \\
\hline
\end{tabular}

$58.3 \%)$, respectively $(p<0.001)$ (Figure 3B). On the other hand, the 5-year overall survival rates in the new $\mathrm{nG} 1, \mathrm{nG} 2$, and nG3 groups (using the new grading system) were $93.8 \%$ (95\% CI: $63.2 \%-99.1 \%), 91.1 \%$ (95\% CI: 80.8\%-96.0\%), and $79.0 \%$ (95\% CI: $55.3 \%-91.1 \%)$, respectively $(p=0.208)$ (Figure 4A). The 5-year recurrence-free survival rates in the new $\mathrm{nG} 1, \mathrm{nG} 2$, and $\mathrm{nG} 3$ groups were $88.5 \%$ (95\% CI: $61.4 \%-97.0 \%$ ), $75.9 \%$ (95\% CI: $63.6 \%-84.5 \%$ ), and $63.1 \%$ (95\% CI: 37.6\%-80.5\%), respectively ( $p=0.407$ ) (Figure 4B).

Next, receiver operating characteristic (ROC) curves were drawn to compare the conventional with the new grading system, so as to assess which grading system is more suitable for identifying prognostic factors in all stages of completely resected lung adenocarcinoma. The ROC curve of the 147 patients that changed histological grade with respect to overall survival, showed that the area under the curve (AUC) was 0.636 (95\% CI: 0.489-0.783) when using the conventional grading system, and 0.603 (95\% CI: 0.452-0.755) when using the new grading system $(p=0.738)$ (Figure $5 \mathrm{~A})$. The ROC curve of 147 patients changed histological grade with respect to recurrence-free survival, showed that the AUC were 0.710 (95\% CI: 0.608-0.811) when using the conventional grading system, and 0.567 (95\% CI: $0.476-0.657)$ when using the new grading system $(p=0.035)$ (Figure $5 \mathrm{~B})$. 
Yasukawa et al: Histological Grade of Adenocarcinoma

Table VI. Univariate analysis of factors influencing the recurrence in all patients after complete resection of the primary lung cancer.

\begin{tabular}{|c|c|c|c|c|}
\hline Factors & Comparison & Hazard ratio & $95 \% \mathrm{CI}$ & $p$-Value \\
\hline Age & $\geq 70$ vs. $<70$ years & 1.143 & $0.778-1.679$ & 0.498 \\
\hline Gender & Male vs. female & 1.118 & $0.764-1.635$ & 0.567 \\
\hline CT findings & Pure GGN vs. other & 0.162 & $0.066-0.400$ & $<0.001$ \\
\hline Location & Peripheral $v s$. other & 0.794 & $0.512-1.231$ & 0.303 \\
\hline Histological grade (conventional) & $\mathrm{cG} 2+3$ vs. $\mathrm{cG} 1$ & 3.058 & $2.382-3.926$ & $<0.001$ \\
\hline Histological grade (new) & $\mathrm{nG} 2+3$ vs. $\mathrm{nG} 1$ & 2.689 & $2.028-3.567$ & $<0.001$ \\
\hline pStage & $\geq \mathrm{II} v s . \mathrm{I}$ & 7.982 & $5.363-11.88$ & $<0.001$ \\
\hline pT & $\geq 2 v s . \leq 1$ & 3.670 & $2.462-5.472$ & $<0.001$ \\
\hline Invasive size of tumor & $>30 \mathrm{vs} . \leq 30 \mathrm{~mm}$ & 3.645 & $2.473-5.371$ & $<0.001$ \\
\hline $\mathrm{pN}$ & $\geq 1$ vs. 0 & 2.734 & $2.214-3.376$ & $<0.001$ \\
\hline PL & Present $v s$. absent & 2.836 & $1.926-4.174$ & $<0.001$ \\
\hline $\mathrm{V}$ & Present $v s$. absent & 5.014 & $3.379-7.441$ & $<0.001$ \\
\hline LY & Present $v s$. absent & 5.744 & $3.667-8.996$ & $<0.001$ \\
\hline Micropapillary & Present $v s$. absent & 2.318 & $1.317-4.080$ & 0.004 \\
\hline CEA & $\geq 5 \mathrm{vs} .<5 \mathrm{ng} / \mathrm{ml}$ & 2.471 & $1.688-3.618$ & $<0.001$ \\
\hline
\end{tabular}

CEA: Carcinoembryonic antigen; CI: confidence interval; CT: computed tomography; GGN: ground glass nodule; LY: lymphatic vessel invasion factor; PL: pleural invasion factor; V: vascular invasion factor.

Table VII. Multivariate analysis of factors influencing the recurrence of all patients after complete resection of the primary lung cancer using the conventional grading system.

\begin{tabular}{|c|c|c|c|c|}
\hline Factors & Comparison & Hazard ratio & $95 \% \mathrm{CI}$ & $p$-Value \\
\hline Age & $\geq 70 \mathrm{vs} .<70$ years & 1.195 & $0.796-1.795$ & 0.391 \\
\hline Gender & Male $v s$. female & 1.161 & $0.768-1.758$ & 0.479 \\
\hline CT findings & Pure GGN vs. other & 0.665 & $0.250-1.770$ & 0.414 \\
\hline Histological grade (conventional) & $\mathrm{cG} 2+3$ vs. $\mathrm{cG} 1$ & 1.826 & $1.354-2.464$ & $<0.001$ \\
\hline Invasive size of tumor & $>30 \mathrm{vs} . \leq 30 \mathrm{~mm}$ & 2.300 & $1.506-3.513$ & $<0.001$ \\
\hline $\mathrm{pN}$ & $\geq 1$ vs. 0 & 1.853 & $1.384-2.481$ & $<0.001$ \\
\hline PL & Present vs. absent & 0.693 & $0.434-1.105$ & 0.124 \\
\hline V & Present vs. absent & 2.221 & $1.288-3.832$ & $<0.001$ \\
\hline LY & Present $v s$. absent & 1.216 & $0.619-2.390$ & 0.571 \\
\hline CEA & $\geq 5$ vs. $<5 \mathrm{ng} / \mathrm{ml}$ & 1.206 & $0.798-1.824$ & 0.374 \\
\hline
\end{tabular}

CEA: Carcinoembryonic antigen; CI: confidence interval; CT: computed tomography; GGN: ground glass nodule; LY: lymphatic vessel invasion factor; PL: pleural invasion factor; V: vascular invasion factor.

Table VIII. Multivariate analysis of factors influencing the recurrence of all patients after complete resection of the primary lung cancer using the new grading system.

\begin{tabular}{|c|c|c|c|c|}
\hline Factor & Comparison & Hazard ratio & $95 \% \mathrm{CI}$ & $p$-Value \\
\hline Age & $\geq 70 \mathrm{vs} .<70$ years & 1.182 & $0.787-1.776$ & 0.420 \\
\hline Sex & Male $v s$. female & 1.151 & $0.761-1.742$ & 0.505 \\
\hline CT findings & Pure GGN vs. other & 0.591 & $0.221-1.581$ & 0.295 \\
\hline Histological grade (new) & $\mathrm{nG} 2+3$ vs. $\mathrm{nG} 1$ & 1.292 & $0.891-1.888$ & 0.177 \\
\hline Invasive size of tumor & $>30 v s . \leq 30 \mathrm{~mm}$ & 2.498 & $1.641-3.802$ & $<0.001$ \\
\hline $\mathrm{pN}$ & $\geq 1$ vs. 0 & 1.973 & $1.472-2.647$ & $<0.001$ \\
\hline PL & Present vs. absent & 0.739 & $0.459-1.189$ & 0.213 \\
\hline V & Present vs. absent & 2.001 & $1.137-3.522$ & 0.016 \\
\hline LY & Present $v s$. absent & 1.510 & $0.771-2.956$ & 0.229 \\
\hline CEA & $\geq 5 v s .<5 \mathrm{ng} / \mathrm{ml}$ & 1.202 & $0.796-1.816$ & 0.382 \\
\hline
\end{tabular}

CEA: Carcinoembryonic antigen; CI: confidence interval; CT: computed tomography; GGN: ground glass nodule; LY: lymphatic vessel invasion factor; PL: pleural invasion factor; V: vascular invasion factor. 


\section{Discussion}

In this study, the conventional histological grade, which is based on tumor cell differentiation, was shown to be an independent predictive factor of survival and recurrence in patients at all stages of lung-invasive adenocarcinoma. The conventional histological grading system was more predictive for the prognosis of these patients compared to the new grading system. In general, the most significant predictor of recurrence and prognosis in NSCLC patients arises from using the TNM staging system. As each stage comprises a heterogeneous group of tumors with different responses to treatment and overall outcomes, a tumor-related biological prognostic factor would be very valuable for the clinicians treating these patients.

The histological grading could have important prognostic implications $(4,12)$. Histological grade are correlated with an unfavorable prognosis include cell differentiation and vascular invasion (12). The 2004 World Health Organization (WHO) classification (13) described the histological grade for lung adenocarcinoma as: "Grading is based on conventional histological criteria, including the extent to which the architectural pattern of the tumor resembles that of the normal lung tissue, and cytologic atypia grades 1,2, and 3 refer to well-, moderately, and poorly differentiated tumors, respectively". Thus, the degree of tumor cell differentiation, including variations in histological architecture and cell atypia, is an important determinant of tumor biological malignancy in lung adenocarcimoma. The 2015 WHO classification simply defined grade 1 (well differentiated and lepidic predominant), grade 2 (moderately differentiated and acinar or papillary predominant), and grade 3 (poorly differentiated and solid or micropapillary predominant), based on the single most predominant architectural pattern of the adenocarcinoma (3). Sica et al. (5) proposed that the new histological grading system provided a reliable method for the classification of patients with stage I lung adenocarcinoma in terms of disease-free survival, and it was more objective than the conventional grading based on tumor differentiation. Furthermore, recent data suggest that the poorly differentiated solid and micropapillary histological subtypes are predictive of a survival benefit when adjuvant chemotherapy is offered to patients with surgically resected adenocarcinoma $(14,15)$. However, although previous studies have demonstrated that stage I adenocarcinoma can be prognostically stratified using the architectural subtypes, the prognostic value of architectural subtypes in more advanced stages of lung adenocarcinoma remains unclear (8).

Determination of accurate histological grading system might be difficult. Lung-invasive adenocarcinoma consists of a complex heterogeneous mixture of histological patterns. The invasive adenocarcinoma subtypes are now classified predominantly according to the greatest percentage of
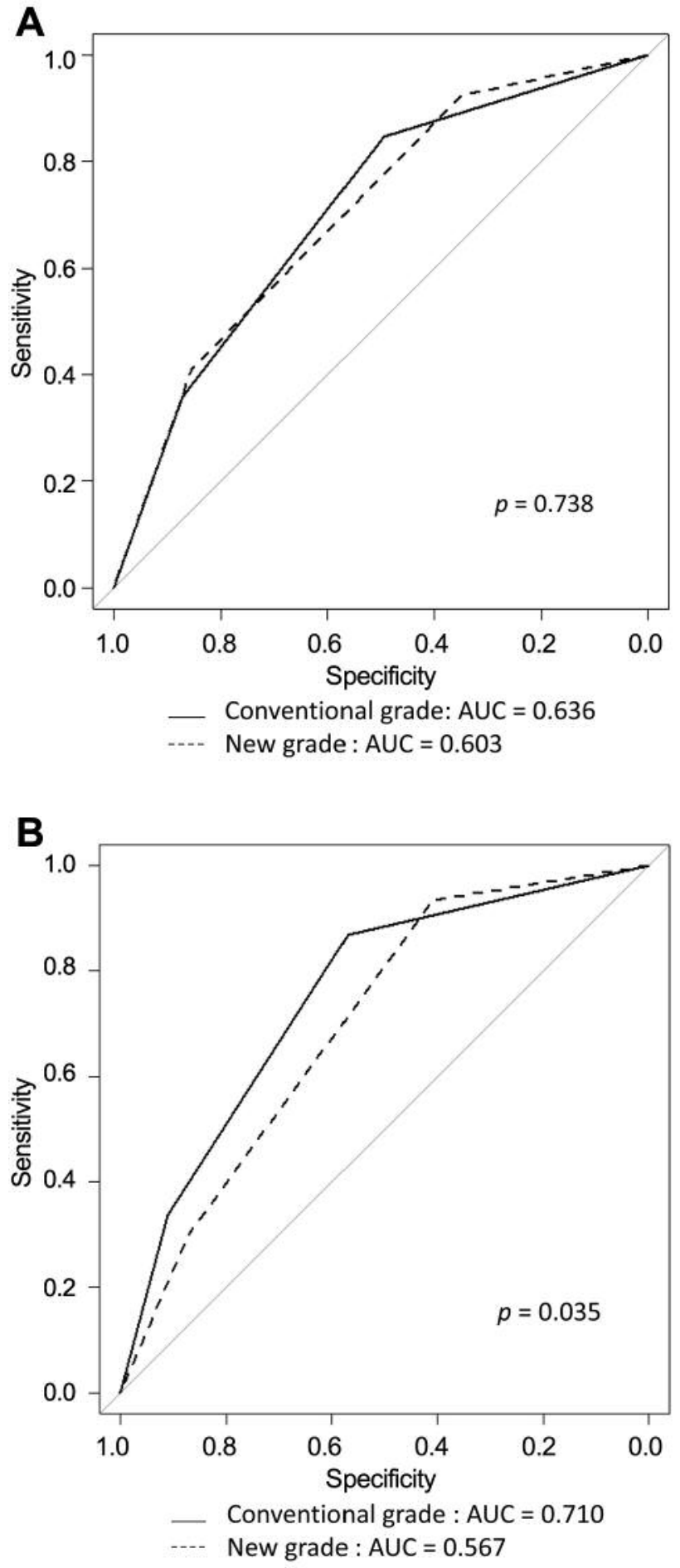

Figure 5. (A) Receiver operatorating characteristic (ROC) curve of 147 patients who changed histological grade according to overall survival. The area under the curve (AUC) was 0.636 (95\% CI: 0.489-0.783) in the conventional grading system, and 0.603 (95\% CI: 0.452-0.755) in the new grading system ( $p=0.738)$. (B) ROC curve of 147 patients who changed histological grade according to recurrence-free survival. The AUC was 0.710 (95\% CI: 0.608-0.811) in the conventional grading system, and 0.567 (95\% CI: 0.476-0.657) in the new grading system $(p=0.035)$. 
histological component subtypes (4). This predominant subtype classification might not reflect the progressive phase of the invasive adenocarcinoma $(16,17)$. Ito et al. (16) reported that acinar or papillary predominant adenocarcinoma with no lepidic characteristics exhibits a significantly poor prognosis compared to acinar or papillary predominant adenocarcinoma with lepidic characteristics. it appears that this definition is still problematic for the grading of lung adenocarcinoma using separately architectural and nuclear approaches or their combination as there may be a divergence between the two grading systems in quite a large number of cases. For example, a tumor composed of the major components of a lepidic pattern with low cytological atypia and the minor components of a solid pattern with high cytological atypia is classified as G3 using the conventional system, while it is classified as G1 using the new system (4, $16,17)$. In this study, several pathologists determined the histological grades of lung adenocarcinoma, focusing on cell differentiation in the period between 2010-2016. The conventional histological grade, based on tumor cell differentiation, was an independent predictor of prognosis and recurrence for all stages.

The TNM classification does not always accurately reflect the tumor cell biological malignancy because of the clinical, pathological, and molecular heterogeneity. Lung adenocarcinoma is the most prevalent pathologic type of NSCLC, and it comprises a heterogeneous mixture of histologic patterns with a broad spectrum of malignant behaviors. Alas, the histological grade, especially when using the conventional grading system, might reflect not only the prognosis, but also the therapeutic efficacy following recurrence. It is true that new grading system for lung invasive adenocarcinoma could be one of the prognostic factors (5-7). However, the conventional grading system might be more suitable for the prognosis of lung adenocarcinoma and cancer recurrence. The new grading system can uniformly offer diagnosis based on the architectural subtypes of lung adenocarcinoma, while the conventional histological grading system can reflect the exact biological malignancy of invasive lung adenocarcinoma based on fitting diagnoses from experienced pathologists. We have previously reported that the conventional histological grade could reflect the biological malignancy of NSCLC and could provide as a simple biomarker for NSCLC in all stages (18). Therefore, we speculate that the conventional histological grading system provides acceptable prognosis and beneficial prediction for adjuvant chemotherapy and for all the stages of resectable NSCLC.

This study has two main limitations: its retrospective design and its small sample size. More validation studies are needed before an appropriated grading system can be recommended for lung invasive adenocarcinoma.
In summary, we found that conventional histological grading is a prognostic factor for completely resected lunginvasive adenocarcinoma, despite the limitations of this study. Future studies should perform additional investigation of histological grading to determine a simple and clear-cut classification that offers optimal prognosis or treatment.

\section{Conflicts of Interest}

The Authors declare that they have no conflict of interest in regard to this study.

\section{Authors' Contributions}

MY is the corresponding author and wrote the manuscript. TN and CO performed the pathological diagnosis. TK, NK, NS, and MY participated in the surgery and postoperative management. $\mathrm{CO}$ and ST supervised the writing of the manuscript. All authors read and approved the final manuscript.

\section{References}

1 Bray F, Ferlay J, Soerjomataram I, Siegel RL, Torre LA and Jemal A: Global cancer statistics 2018: GLOBOCAN estimates of incidence and mortality worldwide for 36 cancers in 185 countries. CA Cancer J Clin 68: 394-424, 2018. PMID: 30207593. DOI: $10.3322 /$ caac. 21492 .

2 Ettinger DS, Wood DE, Aisner DL, Akerley W, Bauman J, Chirieac LR, D'Amico TA, DeCamp MM, Dilling TJ, Dobelbower M, Doebele RC, Govindan R, Gubens MA, Hennon M, Horn L and Komaki R: Non-small cell lung cancer, Version 52017 , NCCN clinical practice guidelines in oncology. J Natl Compr Netw 15: 504-535, 2017. PMID: 28404761.

3 Geisinger K, Rami-Porta R, Moreira AL, Travis WD and Nicholson AG: Lung cancer staging and grading. In: World Health Organization Classification of Tumors. Pathology and Genetics of the Lung, Pleura, Thymus and Heart (Travis WD, Brambilla E, Burke AP, Marx A and Nicholson AG (eds.). Lyon: IARC Press, pp. 14-15, 2015.

4 Travis WD, Brambilla E, Noguchi M, Nicholson AG, Geisinger KR, Yatabe Y, Beer DG, Powell CA, Riely GJ, Van Schil PE, Garg K, Austin JH, Asamura H, Rusch VW, Hirsch FR, Scagliotti G, Mitsudomi T, Huber RM, Ishikawa Y, Jett J, Sanchez-Cespedes M, Sculier JP, Takahashi T, Tsuboi M, Vansteenkiste J, Wistuba I, Yang PC, Aberle D, Brambilla C, Flieder D, Franklin W, Gazdar A, Gould M, Hasleton P, Henderson D, Johnson B, Johnson D, Kerr K, Kuriyama K, Lee JS, Miller VA, Peterson I, Roggli V, Rosell R, Saijo N, Thunnissen E, Tsao $\mathrm{M}$ and Yankelewitz D: International association for the study lung cancer/american thoracic society/ european respiratory society international multidisciplinary classification of lung adenocarcinoma. J Thorac Oncol 6: 244285, 2011. PMID: 21252716. DOI: 10.1097/JTO.0b013e $318206 a 221$.

5 Sica G, Yoshizawa A, Sima CS, Azzoli CG, Downey RJ, Rusch VW, Travis WD and Moreira AL: A grading system of lung adenocarcinoma based on histologic pattern is predictive of disease recurrence in stage I tumors. Am J Surg Pathol 34: 1155-1162, 2010. PMID: 20551825. DOI: 10.1097/PAS.0b013e3181e4ee32. 
6 Hung JJ, Jeng WJ, Chou TY, Hsu WH, Wu KJ, Huang BS and Wu YC: Prognostic value of the new International Association for the Study of Lung Cancer/American Thoracic Society/ European Respiratory Society lung adenocarcinoma classification on death and recurrence in completely resected stage I lung adenocarcinoma. Ann Surg 258: 1079-1086, 2013. PMID: 23532112. DOI: 10.1097/SLA.0b013e31828920c0.

7 Yoshizawa A, Motoi N, Riely GJ, Sima CS, Gerald WL, Kris MG, Park BJ, Rusch VW and Travis WD: Impact of proposed IASLC/ATS/ERS classification of lung adenocarcinoma: prognostic subgroups and implications for further revision of staging based on analysis of 514 stage I cases. Mod Pathol 24: 653-664, 2011. PMID: 21252858. DOI: 10.1038/modpathol.2010.232.

8 Westaway DD, Toon CW, Farzin M, Sioson L, Watson N, Brady PW, Marshman D, Mathur MM and Gill AJ: The International Association for the Study of Lung Cancer/American Thoracic Society/European Respiratory Society grading system has limited prognostic significance in advanced resected pulmonary adenocarcinoma. Pathology 45: 553-558, 2013. PMID: 24018816. DOI: 10.1097/PAT.0b013e32836532ae.

9 Brierley JD, Gospodarowicz MK and Wittekind C: TNM Classification of Malignant Tumours. 8th ed. NJ, Wiley-Blackwell, 2016.

10 Sobin LH, Gospodarowicz MK and Wittekind C: TNM Classification of Malignant Tumours. 7th ed. NJ, Wiley-Blackwell, 2011.

11 Kanda Y: Investigation of the freely available easy-to-use software 'EZR' for medical statistics. Bone Marrow Transplant 48: 452-458, 2013. PMID: 23208313. PMCID: PMC3590441. DOI: $10.1038 / \mathrm{bmt} .2012 .244$.

12 Chung CK, Zaino R, Stryker JA, O’Neill M Jr and DeMuth WE Jr: Carcinoma of the lung: evaluation of histological grade and factors influencing prognosis. Ann Thorac Surg 33: 599-604, 1982. PMID: 7092385.

13 Colby TV, Ohori P, Jambhekar NA, Noguchi M, Rami-Porta R, Petersen I, Henschke C, Franks T, Takahashi T, Vazquez MF, Shimosato Y, Kawai T, Geisinger K, Matsuno Y, Meyerson M, Yokose T, Khoor A, Hanash SM, Westra WH and Jen J: Adenocarcinoma. In: World Health Organization Classification of Tumors. Pathology and Genetics of the Lung, Pleura, Thymus and Heart (Travis WD, Brambilla E, Müller-Hermelink HK and Harris CC (eds.). Lyon, IARC Press, pp. 35-44, 2004.
14 Yoshiya T, Mimae T, Tsutani Y, Tsubokawa N, Sasada S, Miyata Y, Kushitani K, Takeshima Y, Murakami S, Ito H, Nakayama H and Okada M: Prognostic role of subtype classification in smallsized pathologic N0 invasive lung carcinoma. Ann Thorac Surg 102: 1668-1673, 2016. PMID: 27344277. DOI: 10.1016/ j.athoracsur.2016.04.087.

15 Russell PA and Wright GM: Predominant histologic subtype in lung adenocarcinoma predicts benefit from adjuvant chemotherapy in completely resected patients: discovery of a holy grail? Ann Transl Med 4: 16, 2016. PMID: 26855952. PMCID: PMC4716942. DOI: 10.3978/j.issn.2305-5839.2015.10.21.

16 Ito M, Miyata Y, Yoshiya T, Tsutani Y, Mimura T, Murakami S, Ito $\mathrm{H}$, Nakayama $\mathrm{H}$ and Okada $\mathrm{M}$ : Second predominant subtype predicts outcomes of intermediate malignant invasive lung adenocarcinoma. Eur J Cardiothorac Surg 51: 218-222, 2017. PMID: 28186287. DOI: 10.1093/ejcts/ezw318.

17 Takahashi Y, Eguchi T, Kameda K, Lu S, Vaghjiani RG, Tan KS, Travis WD, Jones DR and Adusumilli PS: Histologic subtyping in pathologic stage I-IIA lung adenocarcinoma provides riskbased stratification for surveillance. Oncotarget 9: 35742-35751, 2018. PMID: 30515266. PMCID: PMC6254662. DOI: 10.18632/ oncotarget.26285.

18 Yasukawa M, Sawabata N, Kawaguchi T, Kawai N, Nakai T, Ohbayashi C and Taniguchi S: Histological grade: analysis of prognosis of non-small cell lung cancer after complete resection. In Vivo 32: 1505-1512, 2018. PMID: 30348709. DOI: 10.21873/ invivo.11407. 